\title{
NFkB1 Dichotomously Regulates Pro-Inflammatory and Antiviral Responses in Asthma
}

\author{
Mandy Menzel ${ }^{\mathrm{a}}$ Hamid Akbarshahi ${ }^{\mathrm{a}, \mathrm{b}}$ Irma Mahmutovic Persson ${ }^{\mathrm{a}}$ \\ Cecilia Andersson ${ }^{c}$ Manoj Puthia ${ }^{d}$ Lena Uller $^{a}$ \\ aRespiratory Immunopharmacology, Department of Experimental Medical Sciences, Lund University, Lund, Sweden; \\ ${ }^{\mathrm{b}}$ Respiratory Medicine and Allergology, Department of Clinical Sciences Lund, Lund University, Lund, Sweden; \\ 'Respiratory Cell Biology, Department of Experimental Medical Sciences, Lund University, Lund, Sweden; \\ dDivision of Dermatology and Venerology, Department of Clinical Sciences Lund, Lund University, Lund, Sweden
}

\section{Keywords}

Antiviral immunity · Asthma · Inflammation · Nuclear factor kappa B signaling

\begin{abstract}
Asthma exacerbations are commonly triggered by rhinovirus infections. Viruses can activate the NFKB pathway resulting in airway inflammation and increased Th2 cytokine expression. NFKB signaling is also involved in early activation of IFN $\beta$, which is a central mediator of antiviral responses to rhinovirus infection. Using a mouse model, this study tests our hypothesis that NFKB signaling is involved in impaired IFN $\beta$ production at viral-induced asthma exacerbations. $\mathrm{C} 57 \mathrm{BL} / 6$ wild-type and $\mathrm{NFKB} 1^{-/}$mice were challenged with house dust mite for 3 weeks and were subsequently stimulated with the rhinoviral mimic poly(l:C). General lung inflammatory parameters and levels of the Th2 upstream cytokine IL-33 were measured after allergen challenge. At exacerbation, production of IFN $\beta$ and antiviral proteins as well as gene expression of pattern recognition receptors and IRF3/ IRF7 was assessed. In the asthma exacerbation mouse mod-
\end{abstract}

el, lack of NFKB1 resulted in lower levels of IL-33 after allergen challenge alone and was associated with reduced eosinophilia. At exacerbation, mice deficient in NFkB1 exhibited enhanced expression of IFN $\beta$ and antiviral proteins. This was accompanied by increased IRF3/IRF7 expression and induction of pattern recognition receptor expression. In a human asthma dataset, a negative correlation between IRF3 and NFKB1 expression was observed. NFKB may impair antiviral responses at exacerbation, possibly by reducing expression of the transcription factors IRF3/IRF7. These findings suggest a therapeutic potential for targeting NFKB pathways at viral infection-induced exacerbations.

$$
\begin{aligned}
& \text { () } 2021 \text { The Author(s) } \\
& \text { Published by S. Karger AG, Basel }
\end{aligned}
$$

\section{Introduction}

Asthma is a chronic respiratory disease characterized by wheezing, coughing, shortness of breath, and increased mucus production. Persistent airway inflammation is an

M.M. and H.A. should be considered joint first authors.
C 2021 The Author(s)

Published by S. Karger AG, Basel

This is an Open Access article licensed under the Creative Commons Attribution-NonCommercial-4.0 International License (CC BY-NC) (http://www.karger.com/Services/OpenAccessLicense), applicable to the online version of the article only. Usage and distribution for commercial purposes requires written permission.
Correspondence to:

Mandy Menzel, mandy.menzel@med.lu.se 
important feature of asthma. Eosinophil numbers are increased in bronchoalveolar lavage fluid (BALF) and sputum of asthmatics $[1,2]$, resulting in increased secretion of Th2 cytokines and inflammatory mediators that contribute to airway hyper-responsiveness [3]. Environmental stimuli, such as infection with respiratory viruses, can cause exaggerated lower airway inflammation, termed exacerbation.

Rhinoviruses, the most common cause of asthma exacerbation, are recognized by receptors of the airway epithelium. A viral replication intermediate, dsRNA, is sensed by pattern recognition receptors located in the cytoplasm (RIG-I-like helicases) and in the endosomes (TLR3) $[4,5]$, resulting in the activation of transcription factors. Of these, nuclear factor kappa B (NFkB), consisting of the subunits NFkB1 (p105/p50), NFkB2 (p100/ p52), RelA (p65), RelB, and c-Rel, predominantly regulates inflammatory cytokine expression, while interferon regulatory factor (IRF3/IRF7) primarily mediates expression of antiviral interferons. A deficient interferon response to rhinovirus infection has been observed in asthmatics and is associated with attenuated viral clearance [6-8]. According to a recent study, this may be attributable to increased IL-33 expression in asthmatic subjects [9].

As demonstrated in peripheral blood mononuclear cells [10], bronchial biopsies [11], and cultured bronchial epithelial cells [12], NFKB signaling is elevated in asthmatics compared to healthy subjects. In a mouse model of viral-induced asthma exacerbations, activation of the RelA subunit was associated with exaggerated airway inflammation [13]. While the involvement of NFKB signaling in induction of pro-inflammatory cytokines is well established [14], its role in antiviral responses is poorly understood. Recent findings propose a role for $\mathrm{NF \kappa B}$ in the induction of early antiviral responses, both regulating basal IFN $\beta$ expression in uninfected cells and enhancing IFN $\beta$ levels early after infection before the activation of IRF3/IRF7 reaches optimal levels [15]. However, Bartlett et al. [13] demonstrated that knockdown of the RelA did not affect rhinovirus-induced interferon expression, while abrogating expression of pro-inflammatory cytokines.

To our knowledge, there is no study investigating the role of NFKB signaling and its effects on antiviral responses at exacerbation. Here, we show that NFkB1 drives allergic inflammation in house dust mite (HDM)-challenged mice, while impairing antiviral responses in a mouse model of viral stimulus-induced asthma exacerbation.

\section{Materials and Methods}

\section{Human Gene Expression}

For the analysis of the expression of the human NFkB subunits (NFkB1, NFkB2, RelA, RelB, and c-Rel) as well as the correlation analysis of NFKB1 and IRF3, a published human RNA-sequencing dataset was obtained with accession numbers GSE61141 [16] and GSE76226 [17], respectively. The datasets were downloaded from NCBI's Gene Expression Omnibus and processed using the GEOquery package [18]. Expression levels of the genes of interest were extracted and plotted.

\section{Mouse Model}

C57BL/6;129PF2/J wild-type and $\mathrm{NF}_{\mathrm{BB}} 1^{-/-}$mice [19] of 6-8 weeks of age (provided by Catharina Svanborg, Lund University, Lund, Sweden) were challenged intranasally with $25 \mu \mathrm{g}$ HDM (Greer, Lenoir, NC, USA) or saline 3 days/week for 3 weeks and were subsequently exposed to $50 \mu \mathrm{g}$ polyinosinic:polycytidylic acid (poly(I:C); InvivoGen, San Diego, CA, USA) or saline intranasally. The experiment was terminated either $72 \mathrm{~h}$ after the last HDM challenge or $24 \mathrm{~h}$ after the last poly(I:C) stimulation. Lavage of the lungs was performed, and lung tissue was either collected for immunohistochemistry or snap-frozen and stored at $-80^{\circ} \mathrm{C}$ until further processing.

\section{Analysis of Bronchoalveolar Lavage Fluid}

Cytospin of BALF was performed and stained with May-Grünwald/Giemsa. In total, 400 cells were counted and classified as macrophages, eosinophils, neutrophils, and lymphocytes. Total BALF cell count was performed, and total BALF protein concentrations were determined (BCA assay; Pierce, Thermo Scientific, Waltham, MA, USA).

RNA Isolation and Quantification of Gene Expression by qPCR

Mouse lungs were homogenized, and total RNA was extracted (Nucleospin RNA II; Macherey-Nagel, Düren, Germany) and reverse transcribed to cDNA (Precision nanoScript2 reverse transcription kit; PrimerDesign, Southampton, UK). Quantitative real-time PCR was run on an Mx3005P qPCR system (Stratagene, La Jolla, CA, USA) with standard cycling parameters. Primers were obtained from Qiagen (Sollentuna, Sweden) and PrimerDesign (Southampton, UK). Samples were analyzed using the $\Delta \Delta \mathrm{Ct}$ method [20] and related to $18 \mathrm{~S}$ rRNA.

\section{Protein Quantification by Multiplex ELISA}

Levels of cytokines were measured in mouse lung homogenates by Luminex immunoassays according to the manufacturer's instructions (R\&D Systems, Abingdon, UK). Data were acquired on a validated and calibrated Bio-Plex 200 instrument (Bio-Rad Laboratories AB, Solna, Sweden) as per manufacturer's instructions. Cytokine concentrations were normalized to total protein content in the mouse lung homogenates (BCA assay; Pierce, Thermo Scientific, Waltham, MA, USA).

\section{Quantification of IFN $\beta$ by ELISA}

Levels of IFN $\beta$ were measured in BALF according to the manufacturer's instructions (R\&D Systems, Abingdon, UK). 


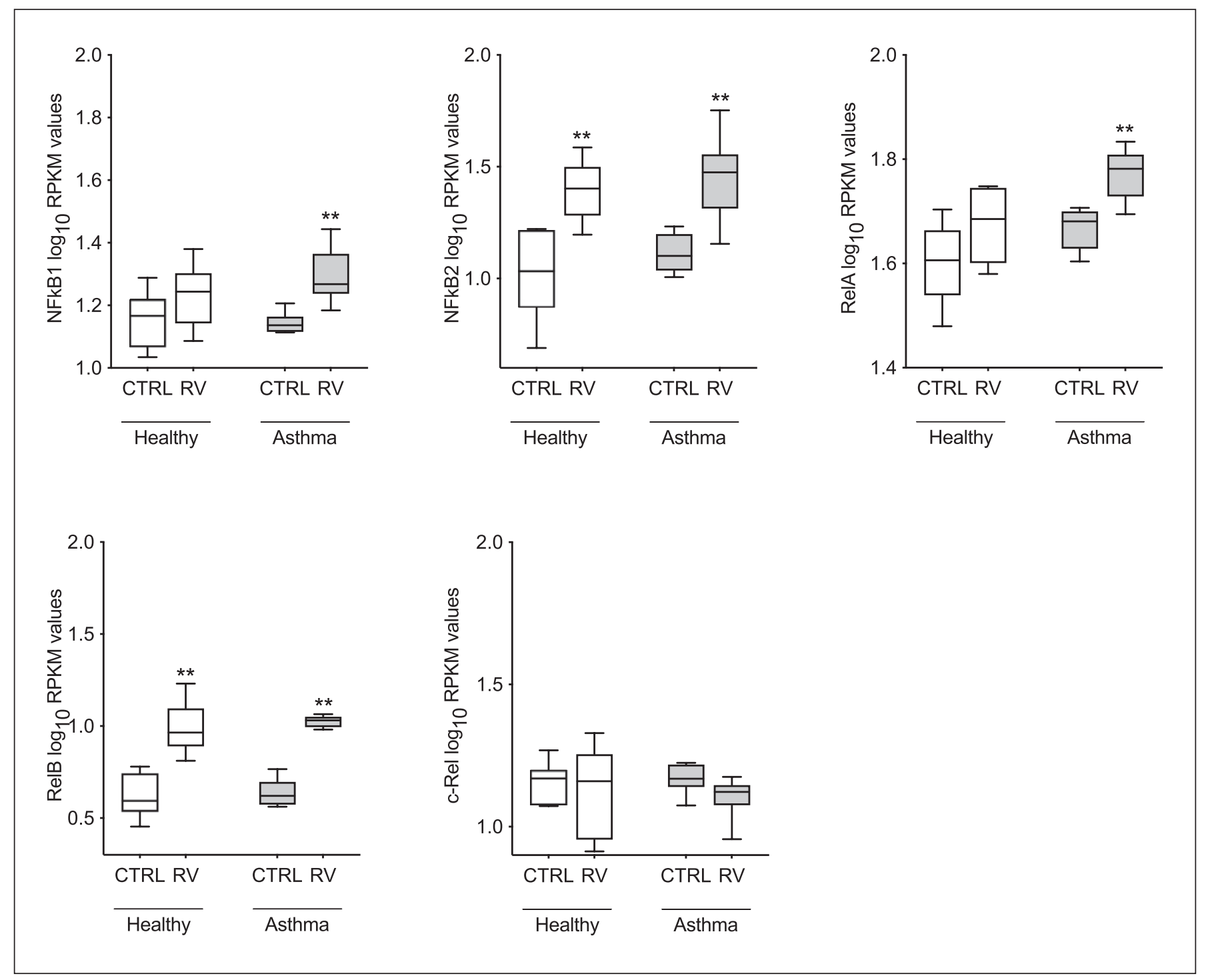

Fig. 1. Expression of NFkB subunits upon rhinovirus infection in differentiated airway epithelial cells of healthy and asthmatic subjects. RNA-sequencing data from air-liquid-interface epithelial cell cultures of healthy and asthmatics before and after ex vivo rhinovirus infection (accession GSE61141) were analyzed for mRNA

\section{Immunohistochemistry Staining}

Mouse lung tissue was paraffin embedded and cut into $4-\mu \mathrm{m}$ sections. After deparaffinization, sections were blocked with $5 \%$ serum for $60 \mathrm{~min}$ at room temperature, followed by overnight incubation with a primary goat anti-mouse IL-33 antibody (R\&D Systems, Abingdon, UK) at $4^{\circ} \mathrm{C}$. Then, sections were incubated with a secondary donkey anti-goat IgG antibody (R\&D Systems, Abingdon, UK), and staining was visualized with 3,3'-diaminobenzidine (Vector Laboratories, BioNordika, Stockholm, Sweden) and counterstained with hematoxylin. Stained sections were scanned using an Aperio slide scanner (Leica Microsystems, Bromma, Sweden). Positive staining was quantified as positivity expression of NFkB1, RelA, NFkB2, RelB, and c-Rel. Data are expressed as $\log _{10}$ RPKM values. Comparison of different groups was performed using Kruskal-Wallis with Wilcoxon post-testing. ${ }^{*} p<$ $0.05 ;{ }^{* *} p<0.01$ CTRL versus RV in each group. RPKM, reads per kilo base per million.

(positive brown pixels divided by all stained pixels) using computerized image analysis on blinded sections by ImageScope (Aperio; Leica Microsystems, Bromma, Sweden). Negative controls (omitting the primary antibody) and isotype controls were used for evaluation of antibody specificity.

\section{Statistical Analysis}

Data are presented as median with interquartile range. Outlier testing using the ROUT method with an FDR of 0.01 was carried out [21]. Group comparisons were performed by Kruskal-Wallis followed by Wilcoxon post-testing using R [22] if not stated otherwise. $p$ values of $<0.05$ were regarded statistically significant. 


\section{Results}

NFאB1 and RelA mRNA Expressions Are Increased upon Rhinovirus Infection in Differentiated Airway Epithelial Cells of Asthmatics but Not Healthy Subjects

First, we determined whether mRNA expression of NFkB subunits was altered in asthmatics upon rhinovirus infection. Publicly available RNA-sequencing data from bronchial epithelial cell cultures of 6 healthy and 6 asthmatics grown at air-liquid-interface before and after 24-h rhinovirus infection were analyzed (accession GSE61141) [16]. Among the analyzed $\mathrm{NF \kappa B}$ subunits $(\mathrm{NF \kappa B} 1$, NFkB2, RelA, RelB, and c-Rel), expression of NFkB1 and RelA was induced upon rhinovirus infection in asthmatic but not in healthy bronchial epithelium (Fig. 1). As RelA may not play a role in antiviral immunity [13], we proceeded to study NFkB1 in a mouse model of asthma exacerbation.

\section{NFאB1 Deficiency Modifies Expression Pattern of}

HDM-Induced Inflammatory Cell Subsets in Mice

Wild-type and $\mathrm{NFkB1}^{-/-}$mice were challenged with saline or HDM 3 times a week for 3 weeks. HDM challenge induced numbers of eosinophils, neutrophils, and lymphocytes in both wild-type and NFkB1-deficient mice, while numbers of macrophages were only increased in NFkB1-deficient mice (see online suppl. Table 1; see www.karger.com/doi/10.1159/000517847 for all online suppl. material). Macrophage levels were higher, and eosinophil levels tended to be lower in mice lacking NFkB1 upon HDM challenge compared to their wild-type littermates (online suppl. Fig. 1).

Levels of NFKB-Dependent Proteins Are Lower in Mice Deficient in NFKB1

We next sought to investigate if the expression of known downstream targets of NFKB, such as CXCL1/KC [23], IL-6 [24], TNF [25], and IL-1 $\beta$ [26], was altered in mice lacking NFkB1. While expression of NFkBdependent proteins was induced after HDM challenge in wild-type mice, mice deficient in NFkB1 had a reduced expression of these cytokines already at baseline, and only a modest induction was observed after HDM challenge (Fig. 2). In contrast, levels of CCL5/RANTES and CCL2/ MCP-1/JE were highly induced in $\mathrm{NF \kappa B}^{-/-}$mice after HDM challenge while there was no change of expression in their wild-type littermates (Fig. 2). Both cytokines are known recruiters of monocytes, and heightened expression in the NFKB1-deficient mice after HDM challenge

NFкB1 Regulates Innate Immunity in Asthma

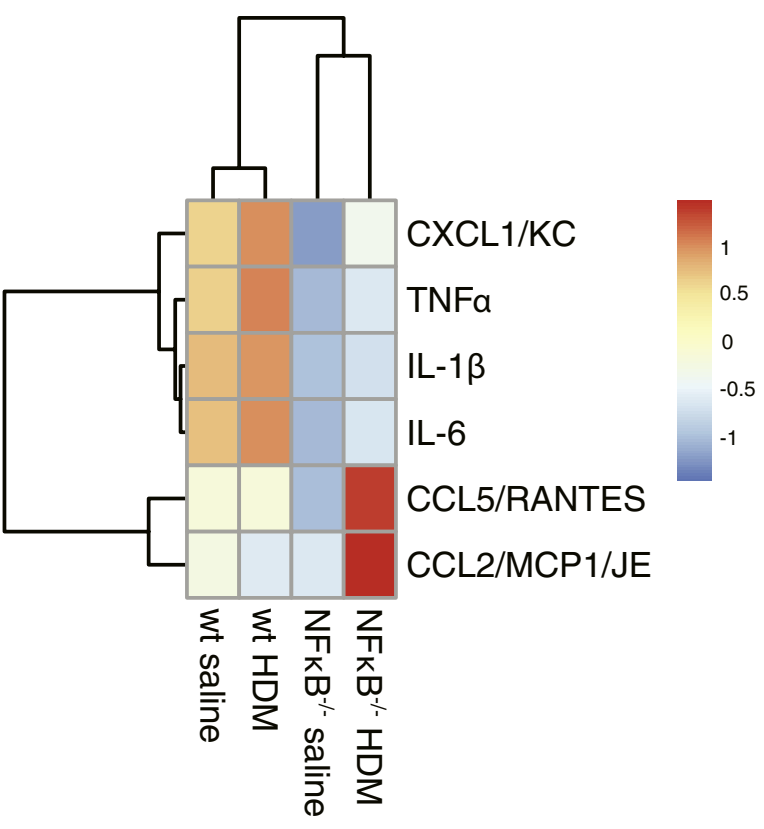

Fig. 2. Expression of $\mathrm{NF \kappa B}$-dependent proteins is reduced in mice deficient in NFKB1. Mice were challenged with saline or HDM 3 days/week for 3 weeks. Expression of NFkB-dependent proteins was measured in lung homogenates and is displayed as a heatmap of mean protein concentrations normalized to total protein content in the mouse lung homogenates with clustering by Euclidian distance. Data were obtained from 5 to 6 mice per group. HDM, house dust mite.

was in accordance with heightened recruitment of macrophages in these mice.

\section{Lack of NFкB1 Reduces HDM-Induced Expression of \\ IL-33}

Levels of the Th2-promoting cytokine IL-33 are elevated in asthmatics and correlate with disease severity [27]. We have previously shown that IL-33 expression is induced after HDM challenge in mice [28]. Here, we observed a trend toward increased expression of IL-33 after allergen challenge in wild-type mice (Fig. 3). Further, we observed no induction of IL-33 gene and protein expression in NFKB1-deficient mice after HDM challenge (Fig. 3a, b). IL-33 positive staining was identified in the airway epithelium and in mononuclear cells within the parenchymal compartment, likely to be alveolar macrophages, and was reduced in NFkB1-deficient mice (Fig. 3c-e). 
Fig. 3. HDM-induced IL-33 expression is reduced in mice lacking $\mathrm{NF} \kappa \mathrm{B} 1$. Mice were challenged with saline or HDM 3 days/week for 3 weeks. IL-33 gene (a) and protein (b) expression was measured in lung homogenates. IL-33-positive cells were quantified in the airways (c) and parenchyma (d) using immunohistochemistry. Data are presented as median with interquartile range. Comparison of different groups was performed using Kruskal-Wallis with Wilcoxon post-testing. ${ }^{*} p<0.05 ;{ }^{* *} p<0.01$. Data from 5 to 6 mice per group were used for analysis. e A representative image of lung IL-33 immunostaining. Scale bar, $100 \mu \mathrm{m}$. HDM, house dust mite.
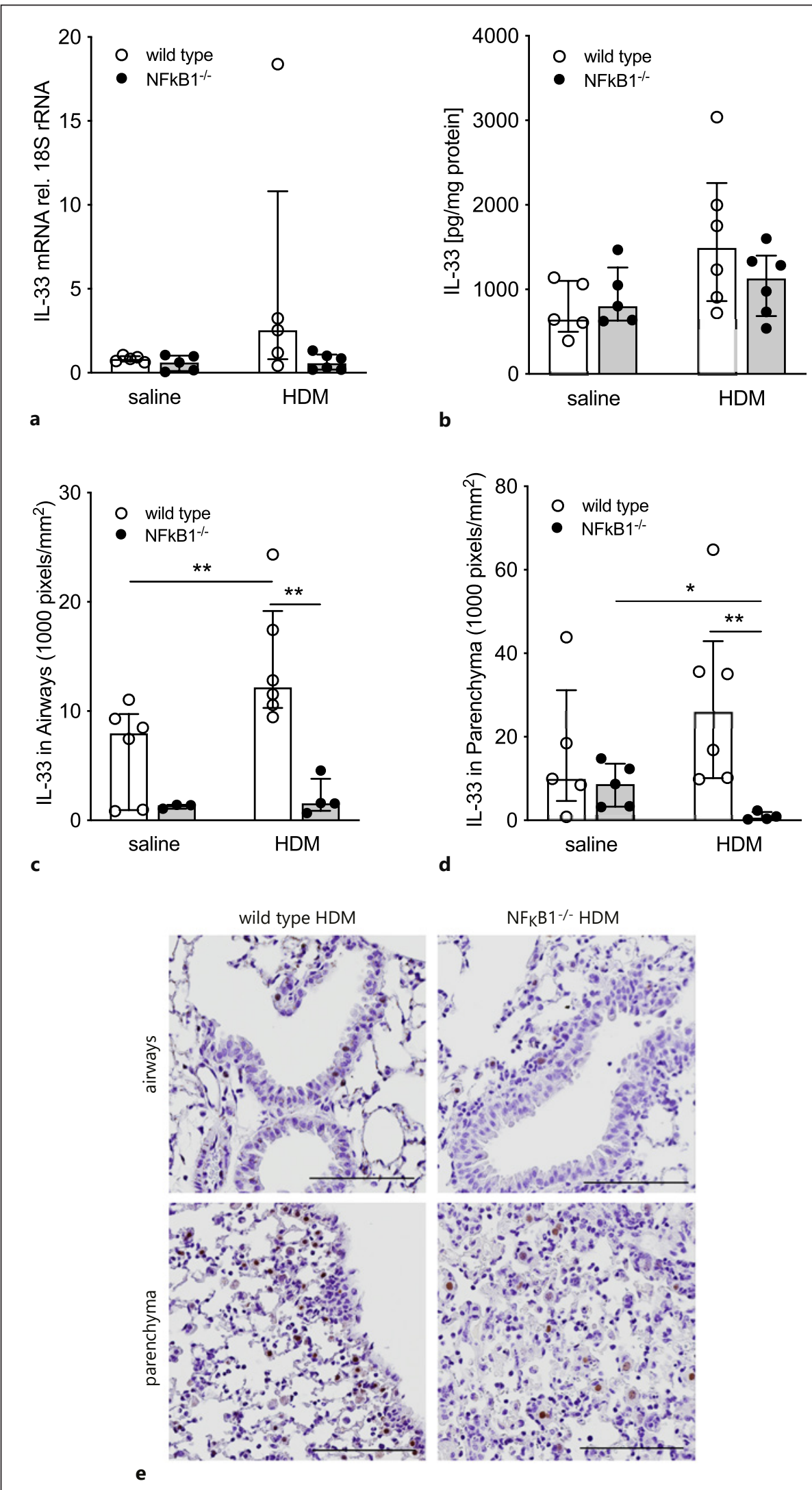

Menzel/Akbarshahi/Mahmutovic Persson/Andersson/Puthia/Uller 
Fig. 4. Enhanced antiviral responses in $\mathrm{NF \kappa B} 1^{-/-}$mice at exacerbation. Mice were challenged with saline or HDM 3 days/ week for 3 weeks and were then stimulated with dsRNA poly(I:C) for 3 days. Lavage of the lungs was performed using PBS $24 \mathrm{~h}$ after the final poly(I:C) exposure. IFN $\beta$ protein levels (a) in bronchoalveolar lavage fluid were measured. Protein concentration of CCL5/RANTES (b), CCL12/MCP5 (c), and IL-10 (d) was measured in lung homogenates. Data are presented as median with interquartile range. Comparison of different groups was performed using Kruskal-Wallis with Wilcoxon post-testing. ${ }^{*} p<0.05 ;{ }^{* *} p<0.01 ;{ }^{* * *} p<0.001$. Data from 5 to 12 mice per group were used for analysis. HDM, house dust mite.

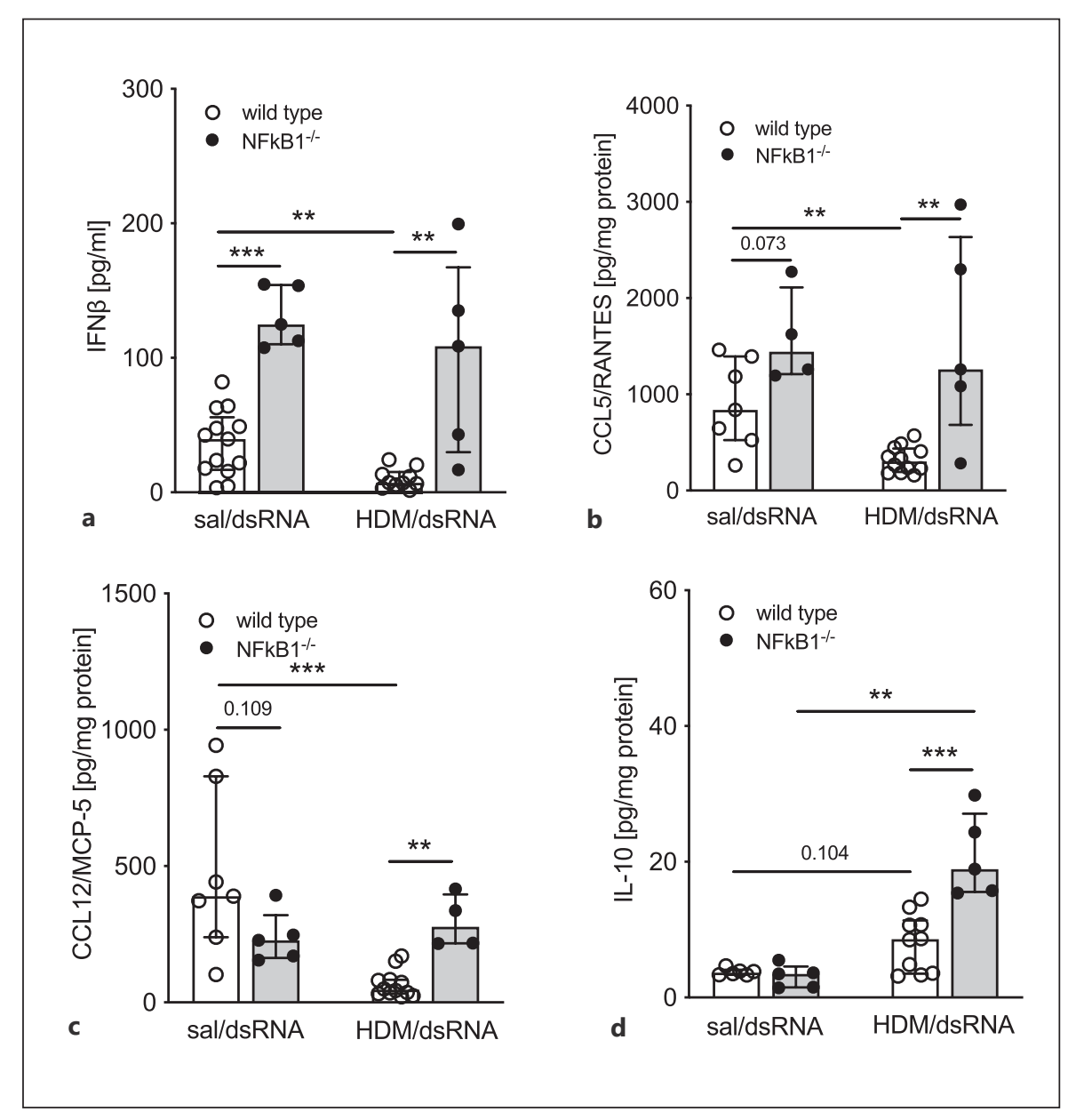

Lack of NFKB1 Modifies Expression Pattern of Inflammatory Cell Subsets at Viral Stimulus-Induced Asthma Exacerbations

In subsequent experiments, wild-type and NFkB1deficient mice were challenged with saline or HDM 3 times a week for 3 weeks to induce allergic airway inflammation. This was followed by stimulation with poly(I:C) or saline for 3 consecutive days to mimic exacerbation. BALF levels of eosinophils, lymphocytes, and to some extent macrophages were induced at exacerbation in both wild-type and $\mathrm{NF \kappa B1} 1^{-/-}$mice. Numbers of neutrophils were not increased at exacerbation in any of the groups but generally higher in $\mathrm{NFKB}^{-/-}$mice (online suppl. Fig. 2).

\section{Antiviral Responses Are Enhanced in $\mathrm{NFKB1}^{-/-}$Mice at Exacerbation}

Antiviral interferon responses are known to be deficient in asthmatics $[6,8]$, possibly contributing to pro- longed and more severe exacerbations [7]. In our mouse model, we observed an induction of IFN $\beta$ after dsRNA stimulation in wild-type mice, which was reduced at exacerbation (Fig. 4a), mimicking clinical findings. Mice deficient in NFKB1 exhibited increased IFN $\beta$ expression in BALF after dsRNA stimulation, which was not reduced at exacerbation (Fig. 4a). Further, protein expression of the interferon-inducible chemokines CCL5/ RANTES and CCL12/MCP-5 [29] in lung homogenates was enhanced at exacerbation in mice lacking NFKB1 compared to their wild-type littermates (Fig. 4b, c). Similarly, protein levels of IL-10, a cytokine with antiviral properties [30], were significantly higher in NFkB1-deficient mice at exacerbation compared to wild-type mice (Fig. 4d). In contrast, expression of the Th2-promoting cytokine IL-33 tended to be lower at exacerbation in mice lacking NFKB1 (online suppl. Fig. 3). 

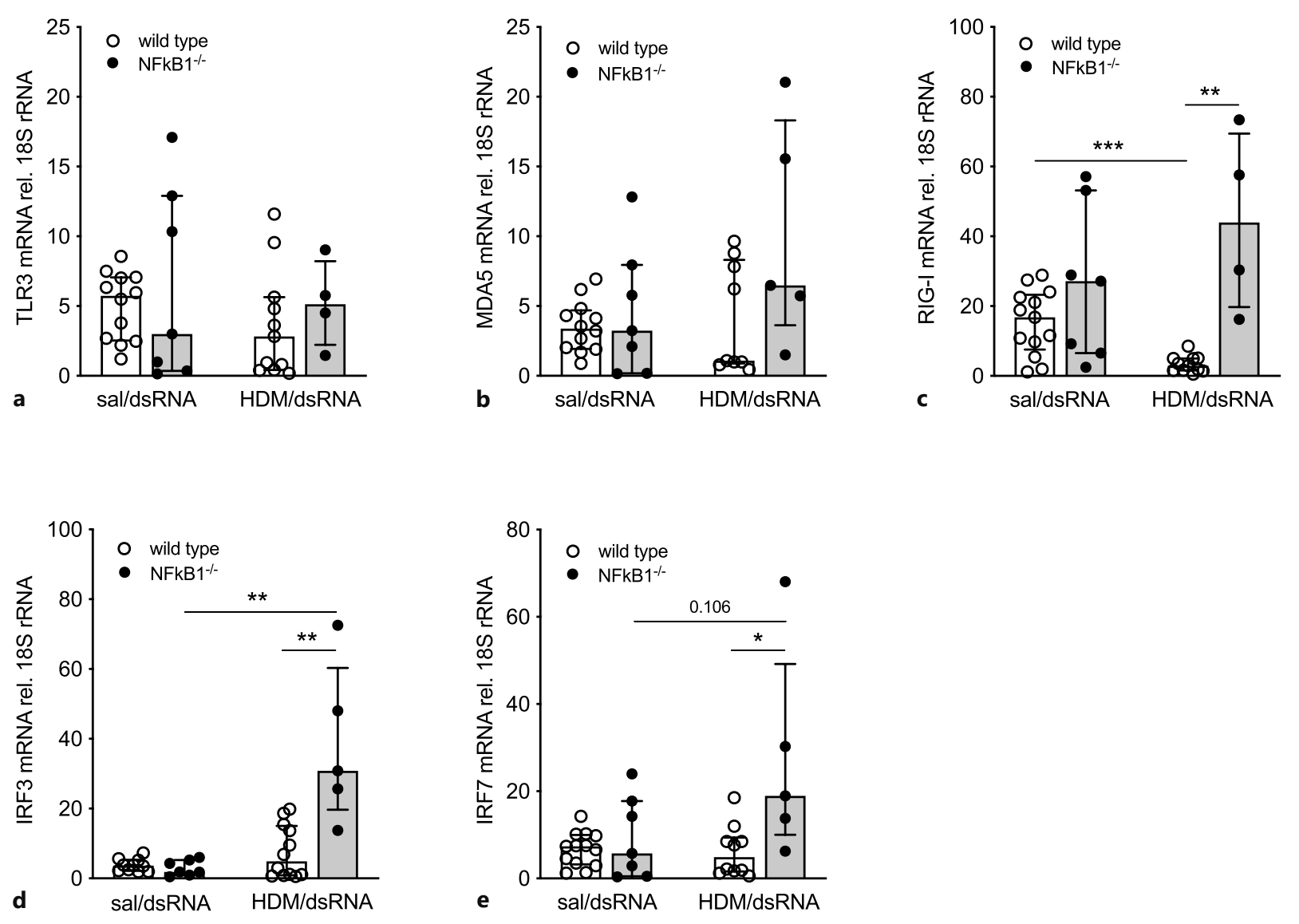

Fig. 5. Antiviral signaling pathway is upregulated in $\mathrm{NF \kappa B} 1^{-/-}$ mice at exacerbation. Mice were challenged with saline or HDM 3 days/week for 3 weeks and were then stimulated with dsRNA poly(I:C) for 3 days. Gene expression of TLR3 (a), MDA5 (b), RIGI (c), IRF3 (d), and IRF7 (e) was measured in lung homogenates.
Data are presented as median with interquartile range. Comparison of different groups was performed using Kruskal-Wallis with Wilcoxon post-testing. ${ }^{*} p<0.05$; ${ }^{* *} p<0.01 ;{ }^{* * *} p<0.001$. Data from 5 to 12 mice per group were used for analysis. HDM, house dust mite.

\section{Pattern Recognition Receptor Expression Is Altered in} $N F \kappa B 1^{-/-}$Mice at Exacerbation

Viral dsRNA is sensed by pattern recognition receptors, such as TLR3 and the RIG-I-like helicases RIG-I and MDA5, activating a signaling cascade that results in production of interferons $[4,5]$. In our mouse asthma exacerbation model, we did not observe a change in TLR3 and MDA5 gene expression at exacerbation in wild-type mice (Fig. 5a, b), while dsRNA-induced RIG-I gene expression was reduced at exacerbation in wild-type mice (Fig. 5c), following the pattern of IFN $\beta$ expression (Fig. 4a). In contrast, expression of RIG-I-like helicases tended to be higher in mice deficient in NFkB1 at exacerbation (Fig. 5b, c).
Lack of NFKB1 Enhances Expression of IRF3 and IRF7 at Exacerbation

The transcription factors IRF3 and IRF7 are central for the transcriptional regulation of IFN $\beta$ expression [31]. In line with previous findings [32], lack of NFkB1 resulted in enhanced expression of IRF3 and IRF7 at exacerbation, which was significantly higher than in the wild-type mice (Fig. 5d, e).

\section{NFאB1 Mediates a Molecular Dichotomy between} Pro-Inflammatory and Antiviral Signaling in Asthma

Findings from our mouse model demonstrate a central role for $\mathrm{NF \kappa B} 1$ in the induction of a pro-inflammatory signaling cascade in response to allergic inflammation as 


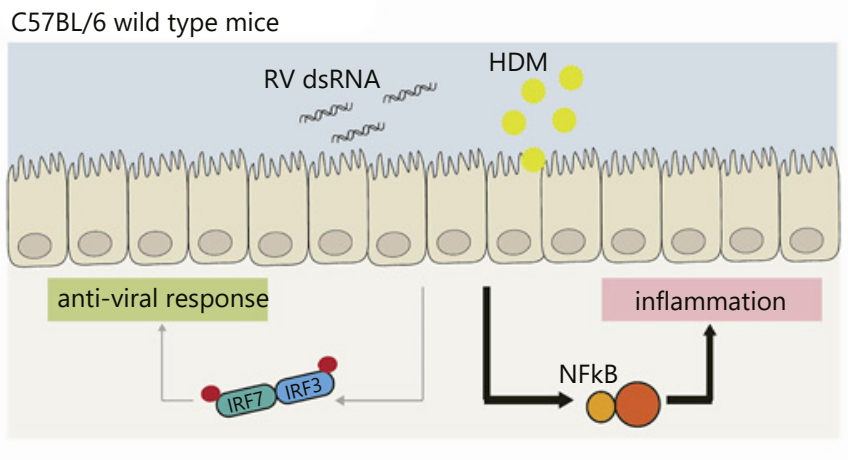

C57BL/6 NFkB1-/- mice
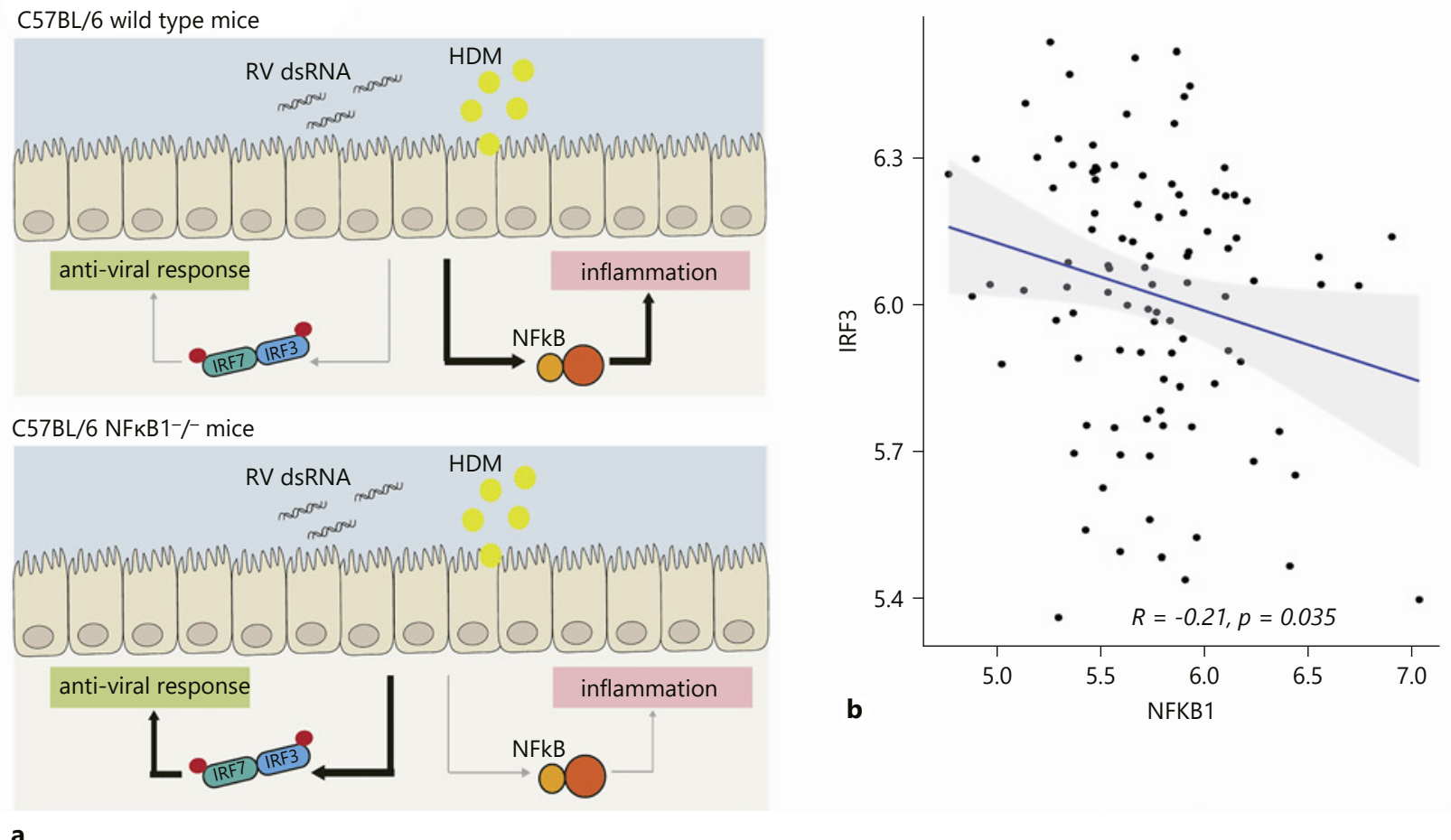

a

Fig. 6. Dichotomy of pro-inflammatory and antiviral signaling. Schematic summary of findings from our asthma exacerbation mouse model describing a balancing of pro-inflammatory and antiviral responses mediated by NFkB1 (a). Correlation analysis between NFKB1 and IRF3 (b) was performed from RNA-sequencing data of bronchial brushings from 99 moderate-to-severe asthmat- ics as part of the Unbiased BIOmarkers in Prediction of Respiratory Disease outcomes (U-BIOPRED) project (accession GSE76226). Correlations were analyzed by Pearson. For correlation with a $p$ value below 0.05 , and thus regarded statistically significant, linear regression was employed. HDM, house dust mite.

\section{Discussion/Conclusion}

The NFkB pathway plays a main role in airway inflammation, and asthmatic patients may display heightened activity of this transcription factor [10-12]. Respiratory viral infections, especially involving rhinovirus, are common triggers of asthma exacerbations and are known to activate NFKB signaling. NFKB has been found to be involved in the very early induction of IFN $\beta$ after viral infection [15]. However, knockdown of RelA in a mouse rhinovirus infection model did not result in altered expression of viral-induced IFN $\beta$ [13]. The role of NFkB in mediating antiviral responses at viral-induced asthma exacerbation thus remains controversial. The present translational data, involving a mouse model of viral stimulusinduced asthma exacerbation, supports the possibility 
that NFkB1 promotes inflammatory immune responses while attenuating IFN $\beta$ expression.

Using a pre-existing RNA-sequencing dataset [16], we showed that NFKB1 is exclusively induced in asthma bronchial epithelial cells after rhinovirus infection, suggesting a functional role for this subunit in viral-induced asthma exacerbations. Based on these findings, this study employed a translational mouse model of asthma exacerbation involving NFkB1-deficient mice. Our data demonstrated a role and involved mechanisms for $\mathrm{NF \kappa B} 1$ in the induction of allergic airway inflammation as well as in the impairment of antiviral responses.

In our mouse model of allergic airway inflammation, lack of NFKB1 resulted in a markedly reduced expression of NFkB-dependent proteins, confirming a functional knockdown. Further, mice deficient in NFkB1 exhibited higher numbers of macrophages but reduced levels of eosinophils upon HDM challenge than their wild-type counterparts, as also shown by others [33, 34]. Eosinophils express the IL-33 receptor ST2 on their surface through which IL-33 can regulate eosinophil function [35]. In line with a decreased eosinophil count, we observed reduced expression of IL-33 after allergen challenge in mice lacking $\mathrm{NF \kappa B} 1$. While signaling pathways leading to IL-33 production are not well studied, our findings and those of others [36] suggest that IL-33 expression - at least in the context of allergic airway inflammation in mice - is NFkB1 dependent.

At exacerbation, higher numbers of neutrophils were observed in NFkB1-deficient mice, suggesting an increased Th1/Th2 ratio in these mice. Considering that a predominantly Th2-type inflammation in asthmatics can negatively regulate innate antiviral immunity [37], a shift toward a Th1 environment would also promote type I interferon expression. Our study supported this view: we found that IFN $\beta$ expression was consistently higher in $\mathrm{NF \kappa B}^{-/-}$mice and, unlike in wild-type mice, was not reduced at exacerbation. This is in line with a previous study in which blocking of IкB kinase enhanced IFN $\beta$ expression in macrophages primed with Th2 cytokines [38]. We further demonstrated that enhanced expression of IFN $\beta$ in NFKB1-deficient mice at exacerbation was associated with an upregulation of antiviral signaling mediated by higher gene levels of IRF3 and IRF7. However, our study design does not allow for studying if and how knockout of NFKB1 affects kinetics of the antiviral immune response. This is a limitation and should be addressed in future studies.

In conclusion, we show a dual role for $\mathrm{NF} \kappa \mathrm{B} 1$ in regulating innate immunity by promoting inflammatory and impairing antiviral responses. Considering these data and the unmet need for pharmaceutical interventions preventing or reducing asthma exacerbation, it is suggested that further evaluation of the therapeutic potential for targeting NFKB at exacerbation is warranted.

\section{Statement of Ethics}

Approval from the Regional Laboratory Animal Ethics Committee in Malmö/Lund was obtained for all experiments (Permit No. M36-13). The study followed the ARRIVE guidelines.

\section{Conflict of Interest Statement}

The authors have no conflicts of interest to declare.

\section{Funding Sources}

The study was supported by financial grants from the Swedish Research Council, the Swedish Heart-Lung Foundation, and Konsul Th C Berghs stiftelse.

\section{Author Contributions}

M.M., H.A., I.M.P., and L.U. contributed to the conception and design of the work. M.M., H.A., I.M.P., and L.U. contributed to the acquisition, analysis, and interpretation of the work. C.A. contributed to analysis of IHC data. M.P. bred and provided the mice. M.M. drafted the manuscript, and M.M., H.A., I.M.P., C.A., M.P., and L.U. revised the manuscript. L.U. provided funding and conceived the study including responsibility for the animal ethics permit. All authors have read and approved the submission of the manuscript.

\section{References}

1 Wardlaw AJ, Dunnette S, Gleich GJ, Collins JV, Kay AB. Eosinophils and mast cells in bronchoalveolar lavage in subjects with mild asthma. Relationship to bronchial hyperreactivity. Am Rev Respir Dis. 1988 Jan;137(1): 62-9.

2 Louis R, Sele J, Henket M, Cataldo D, Bettiol J, Seiden L, et al. Sputum eosinophil count in a large population of patients with mild to moderate steroid-naive asthma: distribution and relationship with methacholine bronchial hyperresponsiveness. Allergy. 2002 Oct; 57(10):907-12.

3 Gleich GJ. Mechanisms of eosinophil-associated inflammation. J Allergy Clin Immunol. 2000 Apr;105(4):651-63.

4 Yoneyama M, Fujita T. Function of RIG-Ilike receptors in antiviral innate immunity. J Biol Chem. 2007 May 25;282(21):15315-8. 
5 Kawai T, Akira S. The role of pattern-recognition receptors in innate immunity: update on toll-like receptors. Nat Immunol. 2010 May;11(5):373-84.

6 Wark PA, Johnston SL, Bucchieri F, Powell R, Puddicombe S, Laza-Stanca V, et al. Asthmatic bronchial epithelial cells have a deficient innate immune response to infection with rhinovirus. J Exp Med. 2005 Mar 21;201(6):937-47.

7 Contoli M, Message SD, Laza-Stanca V, Edwards MR, Wark PA, Bartlett NW, et al. Role of deficient type III interferon-lambda production in asthma exacerbations. Nat Med. 2006 Sep;12(9):1023-6.

8 Sykes A, Edwards MR, Macintyre J, del Rosario A, Bakhsoliani E, Trujillo-Torralbo MB, et al. Rhinovirus 16-induced IFN- $\alpha$ and IFN- $\beta$ are deficient in bronchoalveolar lavage cells in asthmatic patients. J Allergy Clin Immunol. 2012 Jun;129(6):1506-e6.

9 Werder RB, Zhang V, Lynch JP, Snape N, Upham JW, Spann K, et al. Chronic IL-33 expression predisposes to virus-induced asthma exacerbations by increasing type 2 inflammation and dampening antiviral immunity. J Allergy Clin Immunol. 2018 May;141(5): 1607-e9.

10 Gagliardo R, Chanez P, Mathieu M, Bruno A, Costanzo G, Gougat C, et al. Persistent activation of nuclear factor-kappaB signaling pathway in severe uncontrolled asthma. Am J Respir Crit Care Med. 2003 Nov 15;168(10): $1190-8$.

11 Hart LA, Krishnan VL, Adcock IM, Barnes PJ, Chung KF. Activation and localization of transcription factor, nuclear factor-kappaB, in asthma. Am J Respir Crit Care Med. 1998 Nov;158(5 Pt 1):1585-92.

12 Zhao S, Qi Y, Liu X, Jiang Q, Liu S, Jiang Y, et al. Activation of NF-kappa B in bronchial epithelial cells from children with asthma. Chin Med J. 2001 Sep;114(9):909-11.

13 Bartlett NW, Slater L, Glanville N, Haas JJ, Caramori G, Casolari P, et al. Defining critical roles for NF- $\mathrm{kB}$ p 65 and type I interferon in innate immunity to rhinovirus. $\mathrm{EMBO} \mathrm{Mol}$ Med. 2012 Dec;4(12):1244-60

14 Baldwin AS Jr. The NF-kappa B and I kappa $B$ proteins: new discoveries and insights. Annu Rev Immunol. 1996;14:649-83.

15 Balachandran S, Beg AA. Defining emerging roles for NF-kappaB in antivirus responses: revisiting the interferon-beta enhanceosome paradigm. PLoS Pathog. 2011 Oct;7(10): e1002165.
16 Bai J, Smock SL, Jackson GR Jr, MacIsaac KD, Huang Y, Mankus C, et al. Phenotypic responses of differentiated asthmatic human airway epithelial cultures to rhinovirus. PLoS One. 2015;10(2):e0118286.

17 Perotin JM, Schofield JPR, Wilson SJ, Ward J, Brandsma J, Strazzeri F, et al. Epithelial dysregulation in obese severe asthmatics with gastro-oesophageal reflux. Eur Respir J. 2019 Jun;53(6): 1900453

18 Davis S, Meltzer PS. GEOquery: a bridge between the gene expression omnibus (GEO) and bioConductor. Bioinformatics. $2007 \mathrm{Jul}$ 15;23(14):1846-7.

19 Sha WC, Liou HC, Tuomanen EI, Baltimore D. Targeted disruption of the p50 subunit of NF-kappa B leads to multifocal defects in immune responses. Cell. 1995 Jan 27;80(2):32130.

20 Schmittgen TD, Livak KJ. Analyzing realtime PCR data by the comparative $\mathrm{C}(\mathrm{T})$ method. Nat Protoc. 2008;3(6):1101-8.

21 Motulsky HJ, Brown RE. Detecting outliers when fitting data with nonlinear regression: a new method based on robust nonlinear regression and the false discovery rate. BMC Bioinformatics. 2006 Mar 9;7:123.

$22 \mathrm{R}$ Core Team. A language and environment for statistical computing. Vienna, Austria: R Foundation for Statistical Computing; 2013.

23 Ohmori Y, Fukumoto S, Hamilton TA. Two structurally distinct kappa B sequence motifs cooperatively control LPS-induced KC gene transcription in mouse macrophages. J Immunol. 1995 Oct 1;155(7):3593-600.

24 Libermann TA, Baltimore D. Activation of interleukin-6 gene expression through the NFkappa B transcription factor. Mol Cell Biol. 1990 May; 10(5):2327-34.

25 Collart MA, Baeuerle P, Vassalli P. Regulation of tumor necrosis factor alpha transcription in macrophages: involvement of four kappa $\mathrm{B}$-like motifs and of constitutive and inducible forms of NF-kappa B. Mol Cell Biol. 1990 Apr;10(4):1498-506.

26 Hiscott J, Marois J, Garoufalis J, D'Addario $\mathrm{M}$, Roulston A, Kwan I, et al. Characterization of a functional NF-kappa B site in the human interleukin 1 beta promoter: evidence for a positive autoregulatory loop. Mol Cell Biol. 1993 Oct; 13(10):6231-40.

27 Momen T, Ahanchian H, Reisi M, Shamsdin SA, Shahsanai A, Keivanfar M. Comparison of interleukin-33 serum levels in asthmatic patients with a control group and relation with the severity of the disease. Int $J$ Prev Med. 2017;8:65.

28 Mahmutovic Persson I, Akbarshahi H, Menzel M, Brandelius A, Uller L. Increased expression of upstream $\mathrm{TH} 2$-cytokines in a mouse model of viral-induced asthma exacerbation. J Transl Med. 2016 Feb 16;14:52.

29 Mori Y, Hirose K, Suzuki K, Nakajima H, Seto $\mathrm{Y}$, Ikeda $\mathrm{K}$, et al. Tyk2 is essential for IFN-alpha-induced gene expression in mast cells. Int Arch Allergy Immunol. 2004 Jun;134(Suppl 1):25-9.

30 Rojas JM, Avia M, Martín V, Sevilla N. IL-10: a multifunctional cytokine in viral infections. J Immunol Res. 2017;2017:6104054.

31 Honda K, Takaoka A, Taniguchi T. Type I interferon [corrected] gene induction by the interferon regulatory factor family of transcription factors. Immunity. 2006 Sep;25(3):34960.

32 Andreakos E. Asthma exacerbations: a molecular dichotomy between antiviral and proinflammatory responses revealed. EMBO Mol Med. 2012 Dec;4(12):1231-3.

33 Yang L, Cohn L, Zhang DH, Homer R, Ray A, Ray P. Essential role of nuclear factor kappaB in the induction of eosinophilia in allergic airway inflammation. J Exp Med. 1998 Nov 2; 188(9):1739-50.

34 Desmet C, Gosset P, Pajak B, Cataldo D, Bentires-Alj M, Lekeux P, et al. Selective blockade of NF-kappa B activity in airway immune cells inhibits the effector phase of experimental asthma. J Immunol. 2004 Nov 1;173(9):576675.

35 Cherry WB, Yoon J, Bartemes KR, Iijima K, Kita H. A novel IL-1 family cytokine, IL-33, potently activates human eosinophils. $\mathrm{J} \mathrm{Al}$ lergy Clin Immunol. 2008 Jun;121(6):148490.

36 Zhang L, Lu R, Zhao G, Pflugfelder SC, Li DQ. TLR-mediated induction of pro-allergic cytokine IL-33 in ocular mucosal epithelium. Int J Biochem Cell Biol. 2011 Sep;43(9):1383-91.

37 Edwards MR, Strong K, Cameron A, Walton RP, Jackson DJ, Johnston SL. Viral infections in allergy and immunology: how allergic inflammation influences viral infections and illness. J Allergy Clin Immunol. 2017 Oct; 140(4):909-20.

38 Menzel M, Kosinski J, Uller L, Akbarshahi H. Rhinovirus-induced IFN $\beta$ expression is NFkB-dependent and regulated by the macrophage microenvironment. Sci Rep. 2019 Sep 16;9(1):13394. 